\title{
Review
}

\section{Coronavirus Disease-2019 Vaccines and the Vaccination Challenges in India: A Review}

\author{
Imran R. Rangraze, MD, MRCP UK, FRCP, FACP'*; Shehla S. Khan, MBBS'; Yakub Sayyad, BHMS² \\ 'RAK College of Medical Sciences, RAK Medical and Health Sciences University, Ras Al-Khaimah, UAE \\ ${ }^{2}$ Al-Shifa Clinic, Pune, Maharashtra 4I I048, India
}

"Corresponding author

Imran R. Rangraze, MD, MRCP UK, FRCP, FACP

Associate Professor, Department of Internal Medicine, RAK College of Medical Sciences, RAK Medical and Health Sciences University, Ras AI-Khaimah, UAE; Phone.0097I-52567|508; E-mail: dr.imranr@gmail.com

\section{Article information}

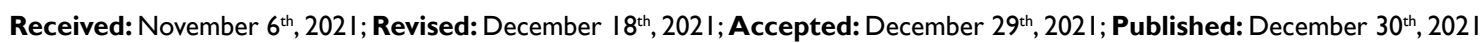

\section{Cite this article}

Rangraze IR, Khan SS, Sayyad Y. Coronavirus disease-2019 vaccines and the vaccination challenges in India:A review. Intern Med Open J. 202I; 5(I): 6-13. doi: $10.17 \mid 40 / 1 M O J-5-117$

\section{ABSTRACT |}

The severe acute respiratory syndrome corona virus-2 (SARS-CoV-2) designated as novel coronavirus is a cause of highly infectious disease referred to as coronavirus disease-2019 (COVID-19). The global pandemic that affected millions of people worldwide has claimed many lives and brought about catastrophe in low-income countries. The high mortality and rapid spread of the infection have brought about an urgent need for a safe and effective vaccine to control the pandemic. In this perspective, it becomes essential to understand the structure, mode of transmission, and virulence of SARS-Cov-2. In this article, an emphasis is made on understanding the infection pathogenesis and the host defense mechanisms against the infection to break the chain of transmission. Furthermore, we have tried to summarize the development and characteristics of different types of COVID-19 vaccines. In addition to this, we have highlighted the challenges of the public health system in the procurement and delivery of the vaccine to the community and especially to the most vulnerable society. It becomes the main priority to find support financially and make the public health system ready to imbibe the importance of vaccination through meticulous strategies so that vaccine reaches out to the community.

\section{Keywords}

SARS-CoV-2; COVID-19; Vaccine; COVID-19 treatment.

\section{BACKGROUND |}

$S^{3}$ ince December 2019, China reported the first corona disease epidemic, caused by severe acute respiratory syndrome coronavirus 2 (SARS-CoV-2), which is currently a worldwide public health concern. ${ }^{1}$ As per the latest World Health Organization (WHO) situation report (date as reported by national authorities by 10:00 hours CET 21 September 2021), India announced $33,531,498$ confirmed cases of coronavirus disease-2019 (COVID-19), and 445,768 deaths. ${ }^{2}$ SARS-CoV-2 is an acute infection of the respiratory system which is primarily transmitted through the respiratory tract, by either respiratory droplets, secretions, or direct contact even for a low infective dose. ${ }^{3,4}$ Otherwise, the virus can be found in stool samples and blood of a severe pneumonia patient, suggesting the possibility of fecal-oral transmission indicating multiple routes of transmission.

This novel coronavirus is associated with respiratory syndrome with a variable degree of severity ranging from paucisymptomatic respiratory illness that ascend into a severe pneumonia and acute respiratory distress syndrome (ARDS) with multiorgan failure. Previous studies reported age as a factor associated with the severity of the symptoms; patients aged 60 -years or above have a greater chance of developing severe respiratory syndromes and a longer period of disease course, unlike patients below the age of 60 -years having comparatively milder symptoms. The most commonly observed signs and symptoms are fever with or without chills, sore throat, cough, loss of smell and loss of taste sensation, etc. However, the majority of the patients are asymptomatic and have mild forms of the disease. The risk of a fatal form of the disease and death due to COVID-19 is the highest among smokers and people with other serious medical disorders, such as malignancy, heart problems, lung disorders, kidney and liver diseases, diabetes, immunocompromised patients, sickle cell disease and obesity. These diseases that are severe in nature are characterized by dyspnea, hypoxia, and extensive lung involvement on imaging. 
at least $40 \mathrm{kgs}$, and c) were at high-risk of progression to severe COVID-19 or hospitalization. The combination of Bamlanivimab and Etesevimab was also granted a EUA in February 2021. Baricitinib is a tyrosine kinase inhibitor; it specifically inhibits Janus $\mathrm{Ki}$ nase 1 and 2 (JAK 1 and 2). Baricitinib in combination with Remdesivir was granted a EUA in patients aged older than 2-years, with suspected or confirmed COVID-19 disease and required assisted ventilator support. ${ }^{7}$ For hospitalized COVID patients requiring oxygen through invasive or non-invasive ventilation, the recommended treatment is dexamethasone alone or in combination with Remdesivir. ${ }^{8}$ Recent data suggest that dexamethasone decreases mortality in such patients. ${ }^{6}$

\section{VACCINES FOR CORONAVIRUS DISEASE-2019}

The vaccine combined with other control measures is the only way to mitigate the public health and economic impact of the pandemic, making it a current priority. In the long run, active immunization is essential for high-risk people to prevent COVID-19. While many countries including India, have taken strong measures to contain the spread of COVID-19 through better protocols, diagnostics, and treatment, the vaccines will provide a solution by enhancing immunity. Vaccines aim to prepare the body by exposing it to an antigen resulting in an immune response capable of either blocking or killing the virus when infected, without causing the actual disease course.

In SARS-CoV, of all the structural proteins, $\mathrm{S}$ protein was found to elicit neutralizing antibodies and considered as a major target antigen for vaccine development. ${ }^{9}$ Historically, the development of the coronavirus vaccine has been very difficult. Previous studies conducted on animal models reported that coronavirus vaccines have been immunogenic yet not effectively preventing spike protein of SARS CoV-2 and was granted EUA for a) mild to moderate COVID-19 cases, b) aged more than 12-years weighing

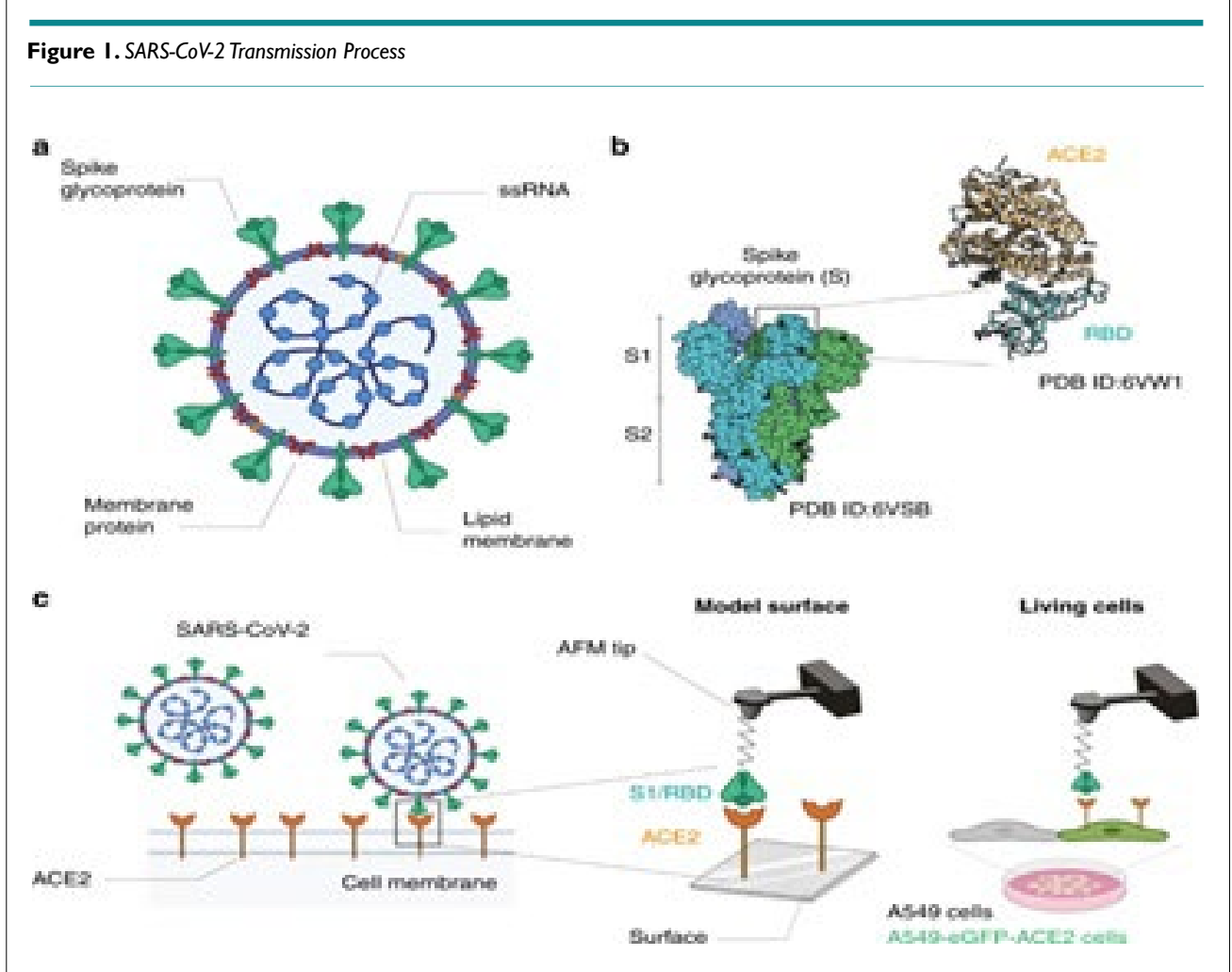


the acquisition of disease. ${ }^{5}$ Furthermore, there is a concern that vaccination, as with coronavirus infection, may not induce longlived immunity and re-infection may be possible. ${ }^{7}$ Previous use of coronavirus vaccines (SARS-CoV and Middle East respiratory syndrome coronavirus (MERS-CoV)) in some animal models raised safety concerns regarding Te 2 mediated immunopathology (Figure $1) .^{8}$

The vaccine against COVID-19 is being developed at a remarkable speed where the first SARS CoV-2 sequences through phase 1 in six-months when compared to the traditional development of a vaccine with a timeline of 3 to 9 -years. The development of a vaccine is a time-consuming process that includes the following phases: Figure 2, Table 1.

As part of the global efforts for the rapid development of a safe and effective COVID-19 vaccine, various scientific techniques like the use of different viruses or viral segments are being developed (Table 2). To this day, a total of 5,776,127,976 vaccine doses have been administered..$^{10}$

Figure 2. Traditional Development of Vaccine

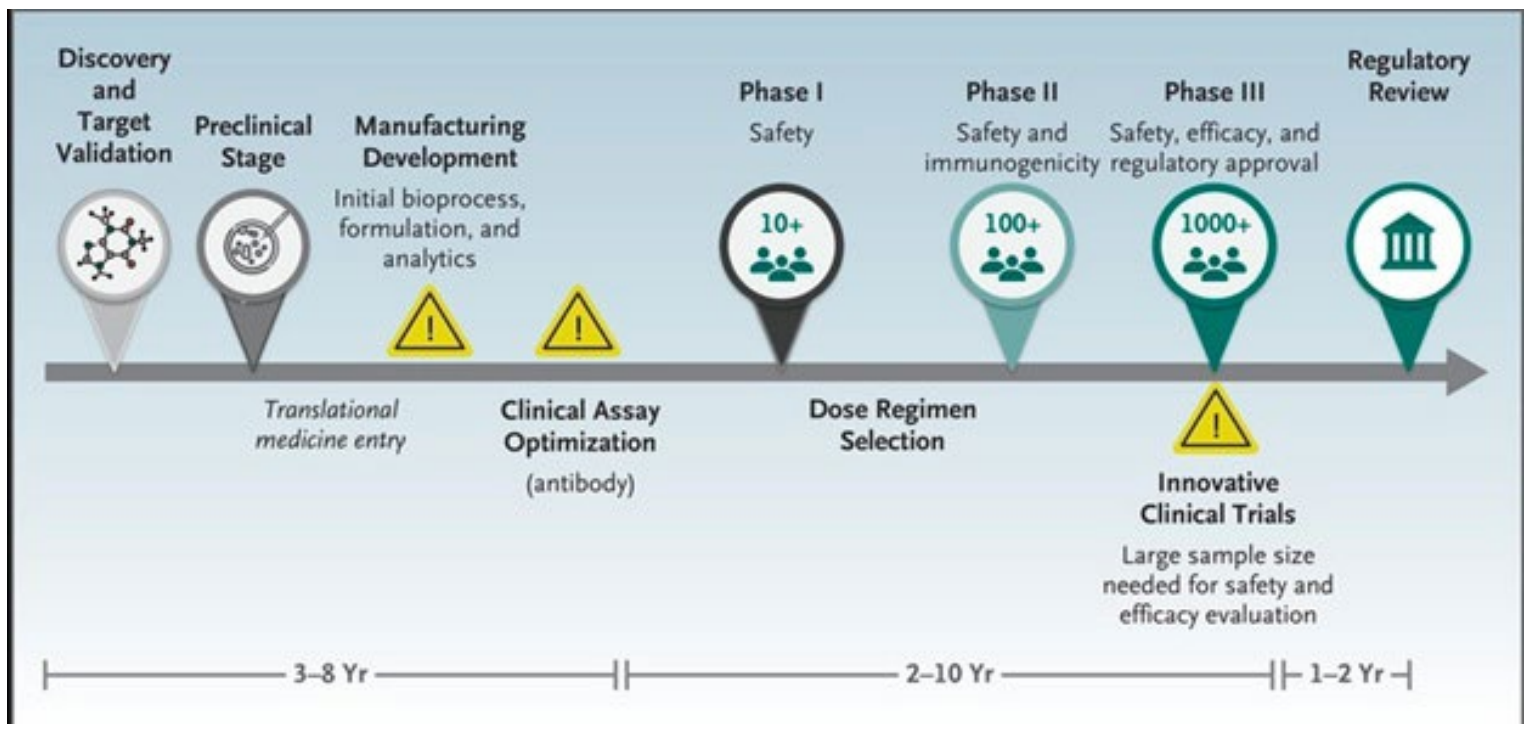

Table I. Phase of Vaccine Development
\begin{tabular}{ll} 
Phase of Vaccine Development/Trial & \multicolumn{1}{c}{ Purpose } \\
\hline Pre-clinical & Vaccine development in laboratory \\
\hline Phase I Clinical trial (8-10 participants) & For testing vaccine safety \\
\hline Phase 2 Clinical trial $(50-100$ participants) & For testing vaccine immunogenicity i.e., production of antibodies against virus \\
\hline Phase 3 Clinical trial $(30,000-50,000)$ & For testing actual protection offered by the vaccine \\
\hline
\end{tabular}

\begin{tabular}{|c|c|c|c|c|c|c|c|c|}
\hline \multicolumn{2}{|c|}{ Type of COVID-19 vaccine } & \multirow{2}{*}{$\frac{\text { Pre-clinical }}{3}$} & \multirow{2}{*}{$\begin{array}{c}\text { Phase I } \\
1\end{array}$} & \multirow[t]{2}{*}{ Phase I/II } & \multirow[t]{2}{*}{ Phase II } & \multirow[t]{2}{*}{ Phase II/III } & \multirow[t]{2}{*}{ Phase III } & \multirow[t]{2}{*}{ Licensed } \\
\hline & Live-attenuated & & & & & & & \\
\hline & Inactivated Virus & 11 & I & 2 & I & & 4 & \\
\hline \multirow{2}{*}{ Viral vector vaccine } & Replicating viral vector & 18 & 1 & 2 & 1 & & 4 & \\
\hline & Non-replicating viral vector & 26 & 6 & & & & 4 & \\
\hline \multirow{2}{*}{ Nucleic acid vaccines } & DNA vaccine & 16 & 2 & 5 & & & & \\
\hline & RNA vaccine & 29 & 2 & 2 & 1 & & 1 & 1 \\
\hline \multirow{2}{*}{ Protein based vaccine } & Protein subunit & 64 & 9 & 5 & 2 & & 1 & \\
\hline & Virus like particle & 17 & & 1 & & 1 & & \\
\hline Unknown & - & 31 & 3 & & & & & \\
\hline Total & & 215 & 25 & 17 & 5 & 1 & 10 & 1 \\
\hline
\end{tabular}


licate within cells) are the two types of viral vector vaccine.

The following are the techniques used to develop COVID-19 vac cines:
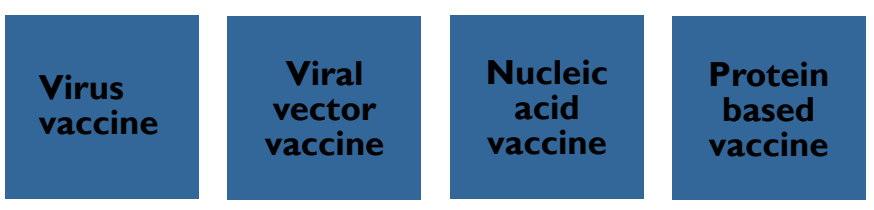

The Following are the Techniques Used to Develop Coronavirus Disease-2019 Vaccines

Virus vaccines: These vaccines use the virus itself in a weakened or inactivated form such as measles and polio (oral) vaccines. There are two types of vaccines under development against coronavirus: weakened virus and inactivated virus vaccines.

Viral-vector vaccines: In the development of these vaccines, a virus (such as adenovirus or measles), is genetically engineered to produce coronavirus proteins in the body, but the virus is weakened and cannot cause disease. The replicating viral vector (can replicate within cells) and non-replicating viral vector (cannot rep-
Nucleic-acid vaccines: In these vaccines, nucleic acid (deoxyribonucleic acid (DNA) or ribonucleic acid (RNA)) is inserted into human cells. This immune response is produced from the human cells which then produce copies of the virus protein. The DNA vaccine and RNA vaccine are the two types of nucleic acid.

Protein-based vaccines: These vaccines use virus protein fragments or protein shells that are injected directly into the body. The two types of protein-based vaccines being developed against the coronavirus are the protein subunit vaccines and virus-like particle vaccines. ${ }^{11}$

\section{TYPES OF CORONAVIRUS DISEASE-2019 VACCINES AND THEIR INDIVIDUAL CHARACTERISTICS |}

The United Nations Children's Fund (UNICEF) in June 2020 has gathered information specifications from 26 vaccine developers and manufacturers on the vaccine (10 manufacturing in China, 6 in India, 3 in the United States of America, 2 each in Belgium, Rus-

\begin{tabular}{|c|c|c|c|}
\hline S.No. & Type of Vaccine & Name & Developer \\
\hline \multirow[b]{2}{*}{1} & \multirow[b]{2}{*}{ mRNA based vaccines } & Comirnaty (BNTI62b2) & Pfizer-BioNTech: Fosun Pharma \\
\hline & & mRNA-1 273 & $\begin{array}{l}\text { Moderna, Biomedical Advanced Research and Development Authority } \\
\text { (BARDA), National Institute of Allergic and Infectious disease (NIAID) }\end{array}$ \\
\hline 2 & Adenovirus vaccine & Covishield aka AZDI 222 & Astrazeneca, Oxford University \\
\hline \multirow[b]{2}{*}{3} & \multirow{2}{*}{$\begin{array}{l}\text { Non-replicating viral } \\
\text { vector }\end{array}$} & JNJ-78436735 & Janssen Pharmaceuticals Companies of Johnson and Johnson \\
\hline & & SputnikV & $\begin{array}{l}\text { Gamaleya Research Institute, Acellena Contract Drug Research and } \\
\text { Development (Russia) }\end{array}$ \\
\hline 4 & Peptide Vaccine & EpiVacCorona & $\begin{array}{l}\text { Federal Budgetary Research Institution State Research Center of } \\
\text { Virology and Biotechnology, Russia }\end{array}$ \\
\hline 5 & Recombinant Vaccine & Convidicea (Ad5-nCoV) & CanSino Biologics, China \\
\hline \multirow{4}{*}{6} & \multirow{4}{*}{ Inactivated Vaccines } & Covaxin & ICMR, Bharat Biotech (India) \\
\hline & & CoronaVac & Sinovac, China \\
\hline & & BBIBP-CorV & Beijing Institute of Biological Products, Sinopharm \\
\hline & & Vaccine still to be named & Wuhan Institute of biological products, Sinopharm \\
\hline
\end{tabular}

\begin{tabular}{|c|c|c|c|c|}
\hline S.No. & Product & Indian Manufacture & Collaborator & Current Stage \\
\hline 1 & $\begin{array}{l}\text { Covishield (Chimpanzee } \\
\text { Adenovirus) }\end{array}$ & Serum Institute of India, Pune & Astra Zeneca & Phase II/III \\
\hline 2 & Covaxin (Inactivated Virus) & $\begin{array}{l}\text { Bharat Biotech International Ltd, } \\
\text { Hyderabad }\end{array}$ & $\begin{array}{l}\text { Indian Council of Medical Re- } \\
\text { search, India }\end{array}$ & Phase III (advanced) \\
\hline 3 & ZyCoV-D (DNA vaccine) & $\begin{array}{l}\text { Cadila Healthcare Ltd,Ahmedabad } \\
\text { (ZydusCadila) }\end{array}$ & $\begin{array}{l}\text { Department of Biotechnology, } \\
\text { India }\end{array}$ & Phase II (advanced) \\
\hline 4 & Sputnik V (Human Adenovirus) & $\begin{array}{l}\text { Trialed and manufactured in India } \\
\text { by Dr. Reddy Lab. }\end{array}$ & Gamaleya National Center, Russia & Phase-II over, Phase-III to start \\
\hline 5 & NVX-CoV2373 (Protein Subunit) & Serum Institute of India, Pune & Novavax & $\mathrm{Ph}$ III under consideration in India \\
\hline 6 & $\begin{array}{l}\text { Recombinant Protein Antigen } \\
\text { based vaccine }\end{array}$ & Biological E Ltd, Hyderabad & MIT, USA & $\begin{array}{l}\text { Phase I plus II human clinical trials } \\
\text { started }\end{array}$ \\
\hline 7 & HGCO 19 (mRNA-basedvaccine) & Genova, Pune & HDT, USA & Pre-clinical animal studies over. \\
\hline 8 & Inactivated rabies vector platform & $\begin{array}{l}\text { Bharat Biotech International Ltd, } \\
\text { Hyderabad }\end{array}$ & Thomas Jefferson University, USA & Pre-clinical (Advanced) \\
\hline 9 & Vesiculo Vax Platform & Aurobindo Pharma Ltd, Hyderabad & Aurovaccine, USA & Pre-clinical (Advanced) \\
\hline
\end{tabular}


to be approved for emergency use and administrated to all people aged more than 18-years with no history of allergy to one of its components.

The common characteristics of the COVID-19 vaccines which were made public on 31 August 2020 from these 26 developers are:

- Most of them are liquid products (few are freeze-dried);

- Majority are intramuscular injections;

- Majority are 2-doses courses;

- The targeted temperature ranges from $2{ }^{\circ} \mathrm{C}$ to $8{ }^{\circ} \mathrm{C}$.

However, there is a possibility of temperature requirements of

$-60{ }^{\circ} \mathrm{C}$ and a shorter half-life.

- The University of Oxford/AstraZeneca vaccine can be stored, transported, and handled at $+2{ }^{\circ} \mathrm{C}$ to $8{ }^{\circ} \mathrm{C} . .^{12}$

- BioNTech/Fosun Pharma/Pfizer vaccine has a recommended temperature condition of $-80{ }^{\circ} \mathrm{C}$ and can be stored for five days at $+2{ }^{\circ} \mathrm{C}$ to $8{ }^{\circ} \mathrm{C} .{ }^{13}$

- The Moderna/NIAID vaccine remains stable at $-20{ }^{\circ} \mathrm{C}$ for up to six months and remains stable at $+2{ }^{\circ} \mathrm{C}$ to $8{ }^{\circ} \mathrm{C}$ for 30 -days and - the Gamaleya institute, Sputnik- $\mathrm{V}$ vaccine can be stored at +2 ${ }^{\circ} \mathrm{C}$ to $8{ }^{\circ} \mathrm{C} .{ }^{14}$

- A recently introduced Johnson \& Johnson's Janssen COVID-19 vaccine (JNJ-78436735) could be kept between $2{ }^{\circ} \mathrm{C}$ and $8{ }^{\circ} \mathrm{C}$ $\left(36^{\circ} \mathrm{F}\right.$ and $46^{\circ} \mathrm{F}$ ) for up to 6 hours or at room temperature (up to $25{ }^{\circ} \mathrm{C}$ or $77^{\circ} \mathrm{F}$ ) for 2 hours. It is a single-shot vaccine and it has reportedly an efficacy of $66.3 \% .^{15}$

\section{CURRENT SITUATION IN INDIA}

India is known as the vaccine manufacturing hub worldwide, contributing $60 \%$ to the global vaccine supply meaning its capacity to manufacture over 3 billion COVID-19 vaccine doses annually. ${ }^{16}$ As of 13 September 2021, a total of 752,238,324 vaccine doses have been administered in India. ${ }^{2}$

The COVID-19 vaccination drive was launched on 16 January 2021, in India. Initially, the doses were made available only for the elderly population and high-risk individuals. Also, the citizens were required to register themselves individually on the Covid vaccine intelligence network (CoWIN) website or the Arogya setu portal which resulted in filling up the slots way too early, hence resulting in fewer administration of jabs during the initial 5-months (1-4 phase). However, later the government waived off the preregistration requirement and started offering vaccinations free of cost. Additionally, from $1^{\text {st }}$ May 2021, everyone older than 18-years of age was made eligible for phase 4 of the vaccination drive. This amendment resulted in acceleration of the vaccination program. ${ }^{17}$

Currently, three vaccines have been approved in India, viz a vir, COVISHIELD (fabricated by the Serum Institute of India (SII)), COVAXIN (developed and manufactured by Bharat Biotech), and SPUTNIK (Gam-COVID-Vac; Gamaleya Research Institute of Epidemiology and Microbiology). ${ }^{17}$

COVISHIELD and COVAXIN were the first vaccines
COVISHIELD: It is known as the Oxford-AstraZeneca Adenovirus vector-based vaccine AZD1222 vaccine based on a replicationdeficient simian adenoviral vector coding the whole length COVID-19 spike glycoprotein (S).

COVAXIN: India's first domestic COVID-19 vaccine based on inactivated COVID-19 virus.

ZyCoV-D: Currently finishing Phase-II trials, it is developed by Cadila Healthcare, Ahmedabad, based on the new plasmid DNA vaccine technology, and supported by the Department of Biotechnology, Government of India. ${ }^{18}$

Individuals with a higher risk of acquiring COVID-19 such as healthcare workers and front-line workers including police, sanitary workers were the first to receive the vaccines. ${ }^{19}$ These vaccines (COVISHIELD or COVAXIN) are free of cost were distributed according to the discretion of the government and the availability status and logistic issues. India is using a well-designed and elaborate micro plan of vaccinating each front-line worker. ${ }^{20}$

It is important to mention that the Serum Institute of India is one of the largest vaccine manufacturers worldwide, in addition, India has a long history of low-cost vaccine production. For instance, it has produced a COVID-19 vaccine with a cost as low as $3 \$$ per dose for the local population and it can be distributed to other developing countries. ${ }^{21}$

Another technology developed in India is the electronic vaccine intelligence network (eVIN) recording data regarding storage, distribution, and usage of vaccines on the ground, facilitating the distribution and tracking nationwide. ${ }^{19}$

India has also dispatched 35.79 million COVID-19 vaccine doses as commercial exports. Yet, it recently lowered the distribution in order to fuel the nationwide vaccination drive. The announcement was reported after the initiation of the rapid increase and second wave all over the country. ${ }^{16}$

\section{THE ADVERSE EFFECTS ASSOCIATED WITH THE CORONAVIRUS DISEASE-2019 VACCINE}

No long-term clinical trial was conducted on the vaccine to assess its side effects in individuals. The vaccine has been accelerated to deploy to the target population at a very stringent schedule, hence safety is very much a concern. It is currently reported that the side effect of the COVID-19 vaccine is very mild that including headache, fatigue, and muscular pain as seen in the vaccine-like PfizerBiotech vaccine. Following the implementation of vaccination, initial reports estimated that rates for anaphylaxis in the United States were 11.1 patients/million doses administered of the PfizerBioNTech vaccine (23 December 2020) and 2.5 patients/million doses after administration of the Moderna vaccine (10 January 
2021). ${ }^{22,23}$ Most reported manifestations were generalized urticaria, diffuse erythematous rash, angioedema, respiratory and airway obstruction signs, and nausea. ${ }^{24}$ In India, the inoculation of the COVID-19 vaccine has started in January 2021, with a target population of three crores of healthcare and frontline workers. Out of the 3.8 lakh who have been vaccinated, 580 cases encountered adverse effects of which two people have developed severe adverse effects. Another detailed continuing prospective long-term safety analysis of COVISHIELD use in the Indian population (February 2021 to May 2022) was conducted on 804 participants. ${ }^{25}$ Findings showed that after the first dose, adverse events were reported in $40 \%$ of patients with a systemic involvement in 248 whereas, after 7-days of the second dose, adverse events occurred in $15.7 \%$ of the individual and systemic in 99. Only one patient was hospitalized while the majority had mild-moderate adverse events and resolved spontaneously showing that the $\mathrm{ChAdOx} 1$ vaccine has a generally favorable safety profile. In another study conducted on 7080 fully vaccinated (mostly COVISHIELD) healthcare workers in Christian Medical College, Vellore India, 9.6\% had development of COVID-19 infection 47-days (34-58-days) after the second dose. Yet, the risk of infection and hospitalization among fully vaccinated Health Care Workers (HCWs) was substantially lower when compared with those unvaccinated (Box). ${ }^{26}$

Who should Get Coronavirus Disease-20 I 9 Vaccine AstraZeneca?

COVID-19 Vaccine AstraZeneca can be used in adults aged under 60-years where the benefits are likely to outweigh the risk and the consumer has made an informed decision based on an understanding of the risks and benefits. People of any age without contraindications who have had their first dose of COVID-19 Vaccine AstraZeneca without any serious adverse events should receive a second dose of the same vaccine.

\section{Benefits of Getting Vaccinated}

- A growing body of evidence has shown COVID-19 vaccines are safe and effective, even for children aged 5 -years and older.

- Millions of people in the United States have received COVID-19 vaccines given the FDA emergency authorization.

- COVID-19 vaccines have undergone and will continue to undergo the most intensive safety monitoring in U.S. history.

- COVID-19 vaccines were developed using scientific methods that have been around for decades.

- Before recommending COVID-19 vaccination for children, scientists conducted clinical trials. The FDA gave the Pfizer BioNTech COVID-19 vaccine emergency authorization to use in children ages 5 -years through 15 -years and full approval to use in people ages 16-years and older.

- Some people have no side effects after COVID-19 vaccination. Furthermore, others reported side effects that may affect their ability to do daily activities, but they should go away within a few days.

- There is no evidence that COVID-19 vaccines cause fertility problems.

- The benefits of COVID-19 vaccination outweigh the known and potential risks. Reports of adverse events, like allergic reactions or myocarditis or pericarditis, are rare.

- Everyone who receives a COVID-19 vaccine can participate in safety monitoring by enrolling themselves and their children ages 5 -years and older in very safe and completing health check-ins after COVID-19 vaccination.

- COVID 19-vaccines are effective and can reduce the risk of getting and spreading the virus that causes COVID-19.

- COVID-19 vaccines also help children and adults from getting seriously ill even if they do get COVID-19.

- There are approximately 28 million children between the ages of 5 and 11-years old in the United States, and there have been nearly 2 million cases of COVID-19 within this age group during the pandemic. COVID-19 can make children very sick, require hospitalization, and some children have even died. Children with underlying medical conditions are more at risk for severe illness compared to children without underlying medical conditions. Therefore, getting children ages 5-years and older vaccinated can help protect them from serious short- and long-term complications.

- Getting everyone ages 5-years and older vaccinated can protect families and communities, including friends and family who are not eligible for vaccination and people at increased risk for severe illness from COVID-19.

\section{CHALLENGES OF DELIVERING THE VACCINE TO THE PUBLIC}

The global public has faced an economic burden for months due to the COVID-19 epidemic. The complete lockdown or community-wide containment was considered as the best vaccine alternative, yet it did cause much loss of employment which hindered the daily living of the people. ${ }^{27}$ The progress of time measures and protocols like wearing a mask, physical distancing, handwashing has paved the way for people to resume back to normal. To everyone's relief, many countries were ready with their vaccine in December

\begin{tabular}{l} 
Box. Weighing up the Potential Benefits Against Risk of Harm from Coronavirus Disease-20I9 Vaccine \\
\hline \multicolumn{1}{c}{ Individual and societal benefits of COVID-19 Vaccine AstraZeneca }
\end{tabular}


2020. The rolling-out of a vaccine against COVID-19 was first administered to the high-risk groups which were the healthcare personals and the frontline workers. However, it was soon realized that there is a sense of resentment towards the COVID-19 vaccination that can be attributed to the myths and false beliefs against the vaccine. Even the doctors, medical students, and nurses are in a wait-and-watch approach before they agree to vaccinate themselves. ${ }^{28}$ Furthermore, the pattern of trust gap regarding the vaccine was seen in the community at large, which demands evidence of the efficacy, safety, technicality, and operation of the vaccine. ${ }^{6}$ However, after the launch of the COVID-19 vaccine by the government of India in 2021, vaccine hesitancy especially among health care workers regarding its safety, efficacy, rolling out strategy and undesirable effects were reported. In a recent cross-sectional study conducted on healthcare workers vaccinated at a tertiary care center of southern Rajasthan India, $80.7 \%$ and $73.2 \%$ out of 3102 of study participants perceived the vaccine as safe and effective respectively. Therefore, findings showed that vaccine hesitancy was due to the apprehension of undesirable effects. ${ }^{29}$ The global public health system has a great responsibility to educate, sensitize people at large to take the vaccination. The role modeling from health officials and other authorities could be of great help too in convincing the community. ${ }^{30}$ The authority in political and health positions must get vaccinated and bring about trust among the people on the COVID-19 vaccines. This calls for more studies and strategies to build the trust of people to comply with the adherence of implementing vaccination for the betterment of civil society. ${ }^{31}$ And last but not the least, when it comes to India, mass gathering during vaccination drives is an important area to focus on in order to prevent further surge in daily cases. Hence the government of India still needs to devise an effective public health strategy to prevent excessive crowding at vaccination centres. Keeping this problem in mind, many states in India have adopted the door-to-door vaccination policy which seems to be a better option, further aiding the huge nation-wide vaccination drive..$^{32,33}$

\section{CONCLUSION}

The international response to this new emerging outbreak has become successively more sophisticated and has been accompanied by a remarkable response from public health bodies and the scientific community which have slowed down the spread of COVID-19 by developing the vaccine. A large number of pharmaceutical companies, research centers and laboratories introduced and tested their vaccine to combat the crisis. After many processes and efforts through various stages that include the pre-clinical stage, development in clinical stages, regulatory review, approval, and manufacturing the vaccines are distributed out in the community. There is an urgent need for a relatively safe and effective COVID-19 vaccine with a clear plan for the preparation and distribution of the vaccine to the community. It becomes the main priority to find support financially and make the public health system ready to imbibe the importance of vaccination through meticulous strategies so that vaccine reaches out to the community.

\section{CONFLICTS OF INTEREST}

The authors declare that they have no conflicts of interest.

\section{REFERENCES}

1. Mao R, Liang J, Shen J, et al. Implications of COVID-19 for patients with pre-existing digestive diseases. Lancet Gastroenterol Hepatol. 2020; 5(5): 425-427. doi: 10.1016/S2468-1253(20)30076-5

2. World Health Organization (WHO). India: WHO Coronavirus Disease (COVID-19) Dashboard. Web site. https://covid19.who. int/region/searo/country/in. Accessed September 22, 2021.

3. Lee P-I, Hsueh P-R. Emerging threats from zoonotic coronaviruses-from SARS and MERS to 2019-nCoV. Journal of Microbiology, Immunology and Infection. 2020; 53: 365-367. doi: 10.1016/j. jmii.2020.02.001

4. Li Q, Guan X, Wu P, et al. Early transmission dynamics in Wuhan, China, of novel coronavirus-infected pneumonia. $N$ Engl J Med. 2020; 382: 1199-1207. doi: 10.1056/NEJMoa2001316

5. Walls AC, Park Y-J, Tortorici MA, Wall A, McGuire AT, Veesler D. Structure, function, and antigenicity of the SARS-CoV-2 spike glycoprotein. Cell. 2020; 183(6): 281-292.e6. doi: 10.1016/j. cell.2020.02.058

6. Graham RL, Donaldson EF, Baric RS. A decade after SARS: strategies for controlling emerging coronaviruses. Nat Rev Microbiol. 2013; 11(12): 836-848. doi: 10.1038/nrmicro3143

7. Roper RL, Rehm KE. SARS vaccines: Where are we? Expert Rev Vaccines. 2009; 8(7): 887-898. doi: 10.1586/erv.09.43

8. Rihan FA, Al-Salti NS, Anwar MNY. Dynamics of coronavirus infection in human. AIP Conference Proceedings. 1982; 020009 (2018): doi: $10.1063 / 1.5045415$

9. Buchholz UJ, Bukreyev A, Yang L, et al. Contributions of the structural proteins of severe acute respiratory syndrome coronavirus to protective immunity. Proc Natl Acad Sci U S A. 2004; 101(26): 9804-9809. doi: 10.1073/pnas.0403492101

10. World Health Organization (WHO). WHO Coronavirus Disease (COVID-19) Dashboard. Available from: https://covid19. who.int/. Accessed June 28, 2020.

11. Callaway E. The race for coronavirus vaccines: A graphical guide. Nature. 2020; 580(7805): 576-577. doi: 10.1038/d41586020-01221-y

12. WHO Ebola Response Team, Agua-Agum J, Allegranzi B, et al. After ebola in West Africa - unpredictable risks, preventable epidemics. N Engl J Med. 2016; 375(6): 587-596. doi: 10.1056/ NEJMsr1513109

13. Pfizer. Pfizer and BioNTech Submit COVID-19 Vaccine Sta- 
bility Data at Standard Freezer Temperature to the U.S. FDA. Web site. Available from: https://www.pfizer.com/news/press-release/ press-release-detail/pfizer-and-biontech-submit-covid-19-vaccinestability-data. Accessed March 25, 2021.

14. Lurie N, Saville M, Hatchett R, Halton J. Developing COVID-19 vaccines at pandemic speed. N Engl J Med. 2020; 382(21): 1969-1973. doi: 10.1056/NEJMp2005630

15. Centers for Disease Control and Prevention (CDC). Johnson \& Johnson's Janssen COVID-19 Vaccine Information. Web site. https://www.cdc.gov/vaccines/covid-19/info-by-product/janssen/index.html. Accessed March 25, 2021.

16. Sharun K, Dhama K. India's role in COVID-19 vaccine diplomacy. J Travel Med. 2021; 28: (taab064). doi: 10.1093/jtm/taab064

17. Choudhary OP, Choudhary P, Singh I. India's COVID-19 vaccination drive: Key challenges and resolutions. Lancet Infect Dis. 2021; 21(11): 1483-1484. doi: 10.1016/S1473-3099(21)00567-3

18. Kumar VM, Pandi-Perumal SR, Trakht I, Thyagarajan SP. Strategy for COVID-19 vaccination in India: The country with the second highest population and number of cases. npj Vaccines. 2021; 6(1): 1-7. doi: 10.1038/s41541-021-00327-2

19. Ministry of Health and Family Welfare. Information regarding COVID-19 vaccine. Web site. https://www.mohfw.gov.in/covid_vaccination/vaccination/index.html. Accessed September 23, 2021.

20. Chakraborty C, Ranjan Sharma A, Bhattacharya M, Lee S-S, Agoramoorthy G. COVID-19 vaccine: Challenges in developing countries and India's initiatives. Infez Med. 2021; 29(1): 165-166.

21. Saha A, Sharma AR, Bhattacharya M, Sharma G, Lee S-S, Chakraborty C. Response to: Status of remdesivir: Not yet beyond question! Arch Med Res. 2021; 52(1): 104-106. doi: 10.1016/j.arcmed.2020.09.005

22. Shimabukuro T, Nair N. Allergic reactions including anaphylaxis after receipt of the first dose of Pfizer-BioNTech COVID-19 vaccine. JAMA. 2021; 325(8): 780-781. doi: 10.1001/jama.2021.0600

23. Centers for Disease Control and Prevention (CDC). Preliminary estimates of the prevalence of selected underlying health conditions among patients with coronavirus disease 2019 - United States, February 12-March 28, 2020. Web site. https://www.cdc. gov/mmwr/volumes/69/wr/mm6913e2.htm. Accessed April 22, 2020 .

24. Shimabukuro TT, Cole M, Su JR. Reports of anaphylaxis af- ter receipt of mRNA COVID-19 vaccines in the US-December 14, 2020-January 18, 2021. JAMA. 2021; 325(11): 1101-1102. doi: 10.1001/jama.2021.1967

25. Kaur U, Ojha B, Pathak BK, et al. A prospective observational safety study on ChAdOx1 nCoV-19 corona virus vaccine (recombinant) use in healthcare workers-first results from India. EClinicalMedicine. 2021; 38: 101038. doi: 10.1016/j.eclinm.2021.101038

26. Victor PJ, Mathews KP, Paul H, Mammen JJ, Murugesan M. Protective effect of COVID-19 vaccine among health care workers during the second wave of the pandemic in India. Mayo Clinic Proceedings. 2021; 96(9): 2493-2494. doi: 10.1016/j.mayocp.2021.06.003

27. Krishan K, Kanchan T. Lockdown is an effective "vaccine" against COVID-19: A message from India. J Infect Dev Ctries. 2020 Jun 30;14(6):545-546. doi: 10.3855/jidc.12931

28. Vergara RJD, Sarmiento PJD, Lagman JDN. Building public trust: A response to COVID-19 vaccine hesitancy predicament. Journal of Public Health. 2021; (fdaa282). doi: 10.1093/pubmed/ fdaa282

29. Mathur M, Mathur N. Vaccine hesitancy among health care workers: A study amidst COVID-19 vaccine drive in India. Int J Epidemiol. 2021; 50(Supplement_1). doi: 10.1093/ije/dyab168.422

30. Medscape. COVID-19 Treatment: Investigational drugs and other therapies. Web site. Web site. https://emedicine.medscape. com/article/2500116-overview. Accessed March 25, 2021.

31. Thiagarajan K. COVID-19: India is at centre of global vaccine manufacturing, but opacity threatens public trust. BMJ. 2021; 372: n196. doi: 10.1136/bmj.n196

32. Australian Government Department (AGD) of Health. COVID-19 vaccination - Weighing up the potential benefits against risk of harm from COVID-19 Vaccine AstraZeneca. Web site. https:/ / www.health.gov.au/resources/publications/covid-19-vaccination-weighing-up-the-potential-benefits-against-risk-of-harmfrom-covid-19-vaccine-astrazeneca. Accessed December 17, 2021.

33. Centers for Disease Control and Prevention (CDC). Benefits of Getting a COVID-19 Vaccine. Web site. https://www.cdc.gov/ coronavirus/2019-ncov/vaccines/vaccine-benefits.html. Accessed December 17, 2021.

34. The Conversation. London School of Hygiene \& Tropical Medicine. Web site. https://theconversation.com/institutions/ london-school-of-hygiene-and-tropical-medicine-859. Accessed December 4, 2021. 